\title{
Ultra-sonografia ocular em suspeita clínica de endoftalmite
}

\author{
Ultrasound findings in clinical suspected endophthalmitis
}

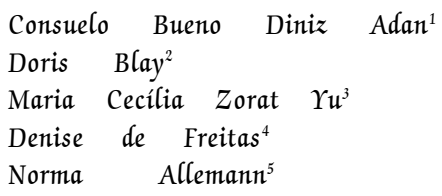

\section{RESUMO}

Objetivo: Apresentar os achados ultra-sonográficos em olhos com suspeita clínica de endoftalmite. Métodos: Estudo prospectivo (agosto/ 97 a abril/99) de olhos com suspeita clínica de endoftalmite infecciosa. Utilizou-se ultra-sonografia ocular (sonda de $10 \mathrm{MHz}$, modos A e B) com técnica de contato direto (UltraScan ${ }^{\circledR}$, Alcon). Resultados microbiológicos da punção da câmara anterior e/ou vítreo, quando presentes, foram anexados à ficha ultra-sonográfica, por ocasião do estudo dos casos. Resultados: Foram estudados 25 olhos (pacientes entre 2 e 79 anos). A fonte de infecção foi exógena em 23 e endógena em 2. Das exógenas, 12 pacientes tinham história de cirurgia prévia ( 7 pós-cirurgia de catarata com implante de LIO, 4 pós-cirurgia de glaucoma, 1 pós-transplante de córnea), 6 referiam história de trauma perfurante, 4 apresentavam úlcera de córnea e 1 fora submetido a sutura de córnea e extração do cristalino após trauma penetrante. Dos casos de etiologia metastática, 1 paciente era diabético e 1 era imunodeprimido. A presença de ecos membranáceos e/ou puntiformes foi a alteração ultra-sonográfica comum a todos os pacientes. Em 2 casos, os ecos tênues e simétricos em relação ao olho normal contralateral possibilitaram afastar a hipótese de comprometimento vítreo. O grau de acometimento do vítreo pareceu ser proporcional à densidade dos ecos membranáceos. A condensação dos ecos, a mobilidade em bloco e a presença de cavitações ou vacúolos denotaram severidade do quadro. Outras alterações ultra-sonográficas comuns foram: espessamento global da coróide (12 casos), descolamento de coróide ( 8 casos) e retina ( 5 casos), impregnação da membrana hialóide ( 4 casos) e comprometimento orbitário (1 caso). Não foi possível correlacionar os achados ultra-sonográficos aos agentes etiológicos. Conclusão: A ultra-sonografia, um método não-invasivo e de fácil acesso, demonstrou ter valor nos casos com suspeita clínica de endoftalmite, principalmente quanto ao grau de comprometimento do segmento posterior.

Descritores: Endoftalmite/ultra-sonografia; Infeções oculares; Ultra-som

\section{INTRODUÇÃO}

A endoftalmite é uma infecção confinada ao interior do globo ocular, extremamente grave pelo risco de levar à cegueira. Conforme a via de contaminação é classificada como exógena ou endógena. A endoftalmite exógena pode ser pós-cirúrgica (principalmente após cirurgia de catarata, de córnea, secundária a bolhas filtrantes), pós-trauma não cirúrgico, ou por contiguidade. A endoftalmite endógena, também chamada de metastática, é decorrente de foco infeccioso que atinge o olho por via hematogênica. Qualquer microorganismo pode causar endoftalmite. A endoftalmite mais 
comum é a pós-cirúrgica causada por bactérias, embora, a literatura nacional seja carente de estatísticas a este respeito. Já as endoftalmites pós-traumáticas podem estar associadas à presença de corpos estranhos intra-oculares, partículas do solo ou vegetais.

A etiopatogenia, apresentação clínica e evolução são variáveis, dependendo do tipo de endoftalmite e do microorganismo envolvido. Suspeita-se de endoftalmite, de modo geral, quando o paciente apresenta dor, sinais inflamatórios do segmento anterior e/ou posterior, associados a antecedente de trauma cirúrgico ou perfurante ou se o paciente é portador de doenças sistêmicas debilitantes como diabetes mellitus, neoplasias ou imunodepressão.

O prognóstico depende do diagnóstico precoce e tratamento adequado.

A ultra-sonografia é um exame não invasivo que auxilia o diagnóstico de várias anomalias oculares e orbitárias ${ }^{(1)}$. No caso das endoftalmites, pode evidenciar se há ou não acometimento do vítreo e possibilita o acompanhamento evolutivo da doença.

\section{OBJETIVOS}

O objetivo é descrever as alterações ultra-sonográficas encontradas em olhos de pacientes com suspeita clínica de endoftalmite, na tentativa de auxiliar no diagnóstico e avaliar a evolução. Não se teve como objetivo testar a sensibilidade e a especificidade do ultra-som no diagnóstico da endoftalmite, pois não há como comparar o exame in vivo com as alterações encontradas. Esta correlação existe somente em estudos experimentais.

\section{MÉTODOS}

Foi realizado estudo prospectivo, no Setor de Ultra-Som do Departamento de Oftalmologia da UNIFESP-EPM, abrangendo o período de 8 de agosto de 1997 a 30 de abril de 1999, perfazendo o total de 20 meses. Os exames foram realizados pelos médicos do setor a quem o protocolo fora explicado previamente. Não foram feitos por um examinador exclusivo devido à urgência dos casos que apareciam nos mais diferentes horários.

$\mathrm{Na}$ data do primeiro exame, preencheu-se ficha com dados da história do paciente e com os achados ultra-sonográficos dispostos sob a forma de múltipla escolha, para facilitar a uniformidade de linguagem entre os examinadores. Outros dados, como resultado microbiológico da punção da câmara anterior e/ou vítreo ou do raspado corneano, quando disponíveis, foram anexados posteriormente à ficha ultra-sonográfica, por ocasião do levantamento da evolução do caso.

No estudo ultra-sonográfico utilizou-se a técnica de contato direto após proteção do transdutor com uma camada fina de filme plástico (PVC- Magipack ${ }^{\circledR}$ ). Os exames foram feitos com transdutor de $10 \mathrm{MHz}$ (UltraScan ${ }^{\circledR}$, Alcon), nos modos A (para análise da amplitude dos ecos) e B (mostrando a localização, extensão e forma dos ecos da cavidade vítrea) e as imagens foram registradas. Exames seriados tiveram as imagens comparadas, na tentativa de demonstrar a evolução do caso.

\section{RESULTADOS}

No período foram avaliados 25 pacientes com suspeita clínica de endoftalmite e cujos exames do polo posterior estavam impossibilitados pela opacidade dos meios.

Dezenove pacientes pertenciam ao sexo masculino e seis ao sexo feminino. A idade variou de 2 anos e 7 meses a 79 anos. Todos os casos eram unilaterais.

Os casos estão dispostos na tabela 1 de acordo com o fator predisponente, os achados ultra-sonográficos, material disponível para o diagnóstico, e sua evolução.

A alteração ultra-sonográfica comum a todos os pacientes foi a presença de ecos membranáceos e/ou puntiformes na cavidade vítrea (Tabela 1) como na figura 1. Em alguns casos os ecos eram tênues e esparsos (exemplo Casos 6 e 21), em outros pacientes, os ecos vítreos apareceram como membranas organizadas formando, algumas vezes, cavitações endovítreas ( $\operatorname{casos} 3,5,9,11,16)$.

Descolamento da coróide (setorial ou total, seroso ou hemorrágico) foi verificado em 8 casos ( $\operatorname{casos} 2,4,7,8,16,20$, 22 e 23) como na figura 3.

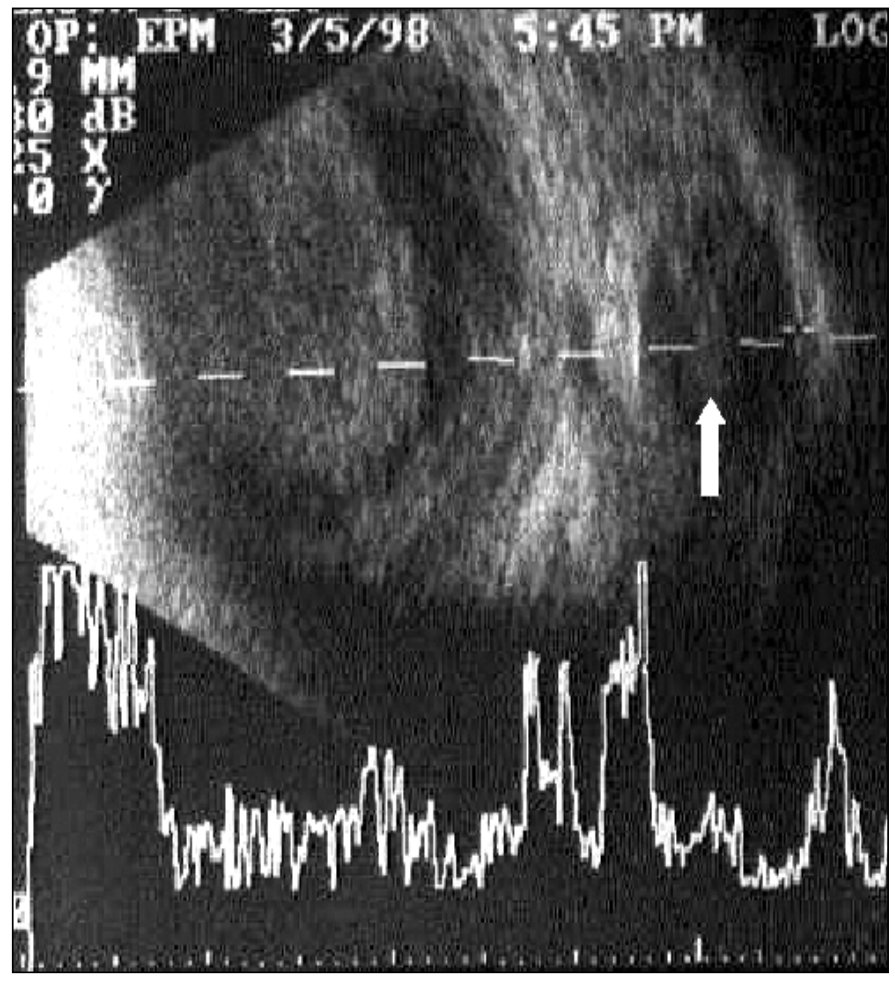

Figura 1 - Paciente com endoftalmite pós-TREC apresenta ecos puntiformes condensados, vacúolos intravítreos, espessamento da parede ocular e abscesso orbitário (seta) (caso 11) 


\begin{tabular}{|c|c|c|c|c|c|}
\hline CASO & $\begin{array}{l}\text { IDADE } \\
\text { (anos) }\end{array}$ & CAUSA E TEMPO & $\begin{array}{l}\text { MATERIAL } \\
\text { PI DIAGNÓSTICO }\end{array}$ & ACHADOS ULTRA-SONOGRÁFICOS & EVOLUÇÃO \\
\hline 1 & 14 & $\begin{array}{l}\text { Trauma Penetrante } \\
\text { (vegetal) } \\
\text { (5 meses) }\end{array}$ & $\begin{array}{l}\text { Punção C.A. } \\
\text { Cultura Negativa } \\
\text { Bact.botão=filamentos } \\
\text { fúngicos leveduriformes }\end{array}$ & $\begin{array}{l}\text { Membranas vítreas móveis } \\
\text { Solução de continuidade da parede ocular } \\
\text { na periferia nasal }\end{array}$ & Úlcera perfurada- TCP \\
\hline 2 & 50 & $\begin{array}{l}\text { Trauma Penetrante } \\
\text { (vegetal) } \\
\text { (2 meses) }\end{array}$ & $\begin{array}{l}\text { Bact. Córnea=filamentos } \\
\text { fúngicos leveduriformes } \\
\text { Cultura Negativa }\end{array}$ & $\begin{array}{l}\text { Múltiplas e densas membranas na C.V. } \\
\text { Pós-TCP= Espessamento e DC } 360^{\circ}\end{array}$ & $\begin{array}{l}\text { Úlcera perfurada-TCP } \\
\text { Phthisis }\end{array}$ \\
\hline 3 & 52 & $\begin{array}{l}\text { Trauma Penetrante } \\
\text { (vidro) } \\
\text { (2 meses) }\end{array}$ & $\begin{array}{l}\text { Bact. Córnea=filamentos } \\
\text { fúngicos leveduriformes } \\
\text { Cultura Negativa }\end{array}$ & $\begin{array}{l}\text { Ecos puntiformes condensados } \\
\text { Vacúolos endovítreos, mobilidade em bloco }\end{array}$ & Úlcera perfurada \\
\hline 4 & 67 & $\begin{array}{l}\text { DMII + Placa } \\
\text { endotelial }\end{array}$ & $\begin{array}{l}\text { Punção V.=neutrófilos } \\
\text { Bact.Córnea Negativo } \\
\text { Cultura Negativa }\end{array}$ & $\begin{array}{l}\text { Ecos puntiformes } \\
\text { Espessamento da coróide, DC periférico } \\
\text { Cristalino sub-luxado inferior }\end{array}$ & \\
\hline 5 & 39 & $\begin{array}{l}\text { Trauma Penetrante } \\
\text { (1 semana) }\end{array}$ & $\begin{array}{l}\text { Punção C.A= } \\
\text { Cocos } G(+) \text { Bacilos } G(-)\end{array}$ & $\begin{array}{l}\text { Ecos membranáceos e puntiformes, } \\
\text { Vacúolos endovítreos, DVP parcial, } \\
\text { Hialóide impregnada DR peripapilar }\end{array}$ & $\begin{array}{l}\text { Tratamento tópico } \\
\text { e sistêmico }\end{array}$ \\
\hline 6 & 79 & Úlcera de Córnea & $\begin{array}{l}\text { Bact. Córnea Negativo } \\
\text { Cultura Negativa }\end{array}$ & $\begin{array}{l}\text { Membranas vítreas tênues retrohialóide } \\
\text { Ecos puntiformes, DVP total }\end{array}$ & Tratamento tópico \\
\hline 7 & 47 & Úlcera de Córnea & & $\begin{array}{l}\text { Membranas vítreas e ecos puntiformes } \\
\text { Espessamento e DC }\end{array}$ & \\
\hline 8 & 58 & EC+LIO +DMII & $\begin{array}{l}\text { Punção C. A= } \\
\text { Filamentos fúngicos } \\
\text { leveduriformes }\end{array}$ & $\begin{array}{l}\text { Membranas vítreas, } \\
\text { Espessamento da coróide } \\
2^{\circ} \mathrm{U}-\mathrm{S}=\mathrm{DC}\end{array}$ & $\begin{array}{l}\text { Tratamento tópico } \\
\text { e sistêmico }\end{array}$ \\
\hline 9 & 60 & $\begin{array}{c}\text { TPC } \\
(10 \text { anos })\end{array}$ & $\begin{array}{l}\text { Punção C.A. e V. } \\
\text { Bact. Negativo } \\
\text { Cultura Negativa }\end{array}$ & $\begin{array}{l}\text { Membranas vítreas móveis } \\
\text { Hialóide impregnada, cavitações endovítreas } \\
\text { Espessamento da coróide }\end{array}$ & $\begin{array}{l}\text { Tratamento } \\
\text { intra-vítreo }\end{array}$ \\
\hline 10 & 70 & Úlcera de córnea & & $\begin{array}{l}\text { Múltiplas e densas membranas na C.V. } \\
\text { Ecos puntiformes } \\
\text { DR total }\end{array}$ & $\begin{array}{l}\text { Úlcera perfurada } \\
\text { Auto-evisceração }\end{array}$ \\
\hline 11 & 5 & $\begin{array}{c}\text { TREC } \\
(4 \text { meses })\end{array}$ & $\begin{array}{l}\text { Punção C.A. e V.= } \\
\text { Diplobacilos G(-) } \\
\text { Cultura Negativa }\end{array}$ & $\begin{array}{l}\text { Ecos puntiformes condensados } \\
\text { Vacúolos endovítreos, mobilidade em bloco } \\
\text { DR 4-9h, espessamento da parede e músculos } \\
\text { Abscesso orbitário }\end{array}$ & Evisceração \\
\hline 12 & 48 & $\begin{array}{l}\text { TREC } \\
(6 \text { anos })\end{array}$ & $\begin{array}{l}\text { Punção C.A. e V. } \\
\text { Cocos G(+) } \\
\text { Cultura Negativa }\end{array}$ & $\begin{array}{l}\text { Ecos puntiformes e membranáceos } \\
\text { Membrana hialóide impregnada } \\
2^{\circ} \mathrm{U}-\mathrm{S}=\text { Espessamento da coróide }\end{array}$ & $\begin{array}{l}\text { Tratamento } \\
\text { intra-vítreo }\end{array}$ \\
\hline 13 & 59 & $\begin{array}{l}\text { Trauma Penetrante } \\
\quad+\text { Sutura+EC } \\
\quad(2 \text { meses })\end{array}$ & $\begin{array}{l}\text { Bact. Córnea }=\text { Cocos } \mathrm{G}(+) \\
\text { Cultura= S.aureus }\end{array}$ & $\begin{array}{l}\text { Ecos puntiformes } \\
\text { DVP total } \\
2^{\circ} \text { U-S }=\text { membranas vítreas }\end{array}$ & \\
\hline 14 & 47 & $\begin{array}{l}\text { EC+LIO } \\
\text { (7 dias) }\end{array}$ & $\begin{array}{l}\text { Punção V. } \\
\text { Cultura Negativa }\end{array}$ & $\begin{array}{l}\text { Ecos puntiformes e membranáceos } \\
\text { DVP parcial }\end{array}$ & $\begin{array}{l}\text { Tratamento } \\
\text { intra-vítreo }\end{array}$ \\
\hline 15 & 70 & $\begin{array}{l}\mathrm{EC}+\mathrm{LIO} \\
(10 \text { dias })\end{array}$ & & $\begin{array}{l}\text { Ecos puntiformes esparsos } \\
\text { DVP total }\end{array}$ & $\begin{array}{l}\text { Tratamento } \\
\text { tópico }\end{array}$ \\
\hline 16 & 58 & $\begin{array}{l}\text { Tubo de Molteno } \\
\text { ( } 2 \text { dias })\end{array}$ & $\begin{array}{l}\text { Punção V.= Cocos } \mathrm{G}(+) \\
\text { Cultura Negativa }\end{array}$ & $\begin{array}{l}\text { Ecos puntiformes e membranáceos } \\
\text { Vacúolos endovítreos, DC, DRtotal }\end{array}$ & Evisceração \\
\hline 17 & & $\mathrm{EC}+\mathrm{LIO}$ & $\begin{array}{l}\text { Punção V. } \\
\text { Bact. Negativo } \\
\text { Cultura Negativa }\end{array}$ & $\begin{array}{l}\text { Membranas vítreas móveis } \\
\text { DVP Total }\end{array}$ & $\begin{array}{l}\text { Tratamento } \\
\text { tópico }\end{array}$ \\
\hline 18 & 53 & $E C+L I O$ & & $\begin{array}{l}\text { Ecos puntiformes } \\
\text { Espessamento de coróide } \\
2^{\circ} \mathrm{U}-\mathrm{S}=\text { Retinosquise das } \\
\text { Temporal Inferior }\end{array}$ & \\
\hline 19 & 7 & $\begin{array}{l}\text { Trauma } \\
\text { (7 dias) }\end{array}$ & $\begin{array}{l}\text { Punção V. } \\
\text { Bact.+Cultura Negativas }\end{array}$ & $\begin{array}{l}\text { Membranas vítreas, DVP parcial } \\
2^{\circ} \text { U-S=DVP total, Membrana pouco móvel } \\
\text { da periferia ao equador } 8-9 \mathrm{~h} \\
3^{\circ} \text { U-S=Aumento vol. cristalino, } \\
\text { Hemorragia subhialoídea } \\
\text { Espessamento da parede }\end{array}$ & $\begin{array}{l}\text { Tratamento } \\
\text { tópico e } \\
\text { sistêmico }\end{array}$ \\
\hline
\end{tabular}


Tabela 1. (continuação) Resumo dos casos com suspeita clínica de endoftalmite e seus achados ultra-sonográficos

\begin{tabular}{|c|c|c|c|c|c|}
\hline CASO & $\begin{array}{l}\text { IDADE } \\
\text { (anos) }\end{array}$ & CAUSA E TEMPO & $\begin{array}{l}\text { MATERIAL } \\
\text { PI DIAGNÓSTICO }\end{array}$ & ACHADOS ULTRA-SONOGRÁFICOS & EVOLUÇÃO \\
\hline 20 & $2 a 7 m$ & $\begin{array}{l}\text { TREC } \\
\text { (2 dias) }\end{array}$ & $\begin{array}{l}\text { Punção V.=hemácias } \\
\text { Cultura Negativa }\end{array}$ & $\begin{array}{l}\text { Ecos puntiformes e membranáceos na } \\
\text { cavidade vítrea. Espessamento da coróide } \\
2^{\circ} \text { U-S =DC hemorrágico, suspeita DR } \\
\text { Hemorragia subhialoídea } \\
3^{\circ} U-S=D C \text { hemorrágico, DR funil fechado } \\
\text { Hemorragia subretiniana }\end{array}$ & $\begin{array}{l}\text { Tratamento } \\
\text { intra-vítreo }\end{array}$ \\
\hline
\end{tabular}

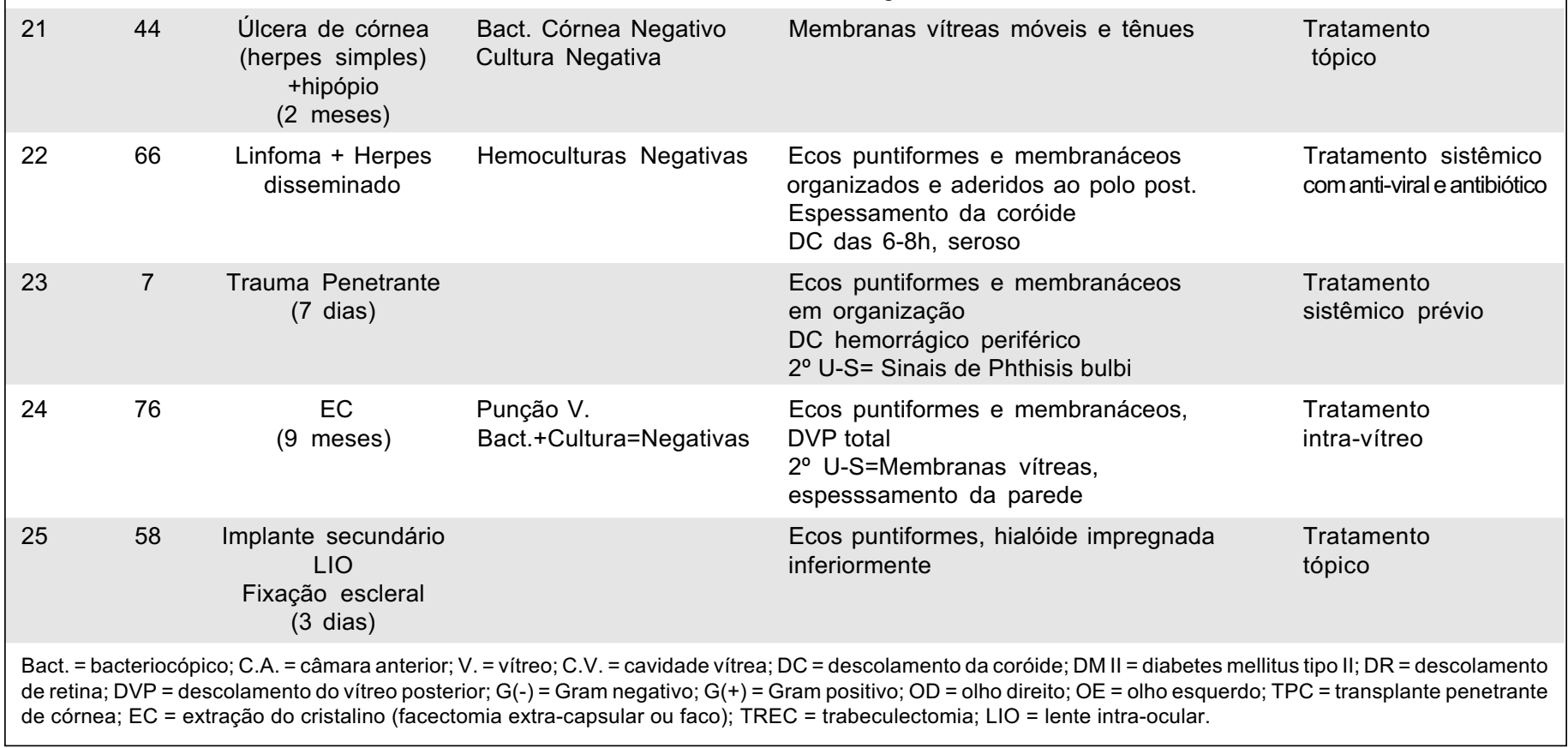

\section{DISCUSSÃO}

Endoftalmite é um processo inflamatório confinado ao interior do globo ocular, que ocorre em resposta à infecção ou ao traumatismo dos tecidos oculares, afetando todas as suas camadas, exceto a esclera ${ }^{(2)}$. "Panoftalmite" refere-se ao processo infeccioso com o acometimento das túnicas oculares internas e estruturas orbitárias, associado à necrose ${ }^{(3)}$. Suspeita-se de endoftalmite quando estão presentes, no olho, sinais inflamatórios associados a baixa acuidade visual e dor.

Dividem-se, classicamente, as endoftalmites em exógenas (associadas a traumas perfurantes ou penetrantes e a cirurgias) e endógenas ou metastáticas. Apesar da grande maioria das endoftalmites ser causada por agentes infecciosos, principalmente bactérias, há casos em que as culturas do material colhido apresentam-se estéreis ${ }^{(2)}$.

Em nosso estudo com 25 pacientes houve predomínio do acometimento no sexo masculino (19 homens, $76 \%$ do total), concordando com os achados citados por outros autores (endoftalmites pós-trauma) ${ }^{(4)}$. Diferentemente, há estudo onde há maior acometimento no sexo feminino ${ }^{(2)}$.

Quanto à fonte de infecção, os números encontrados repetem os dados da literatura: predomínio para as fontes exóge- nas: $92 \%$ foram de origem exógena e $8 \%$ de fonte endógena. As endoftalmites exógenas pós-cirúrgicas foram as formas mais comumente encontradas neste estudo (52\%). Embora não se saiba com exatidão a incidência de endoftalmite seguindo uma cirurgia intra-ocular, parece ser menor que $1 \%{ }^{(2)}$. Numa revisão sobre endoftalmite ${ }^{(3)}$, os autores relatam que a forma mais comum das endoftalmites pós-operatórias é pós-cirurgia da catarata. No estudo em questão, de todas as pós-cirúrgicas, $58 \%$ eram pós-cirurgia para extração do cristalino com implante de lente intra-ocular (LIO), 33\% após procedimentos anti-glaucomatosos e $8,33 \%$ ( 1 caso) tinha história de transplante de córnea prévio. A maior incidência de endoftalmite após cirurgias de catarata é justificada pelo grande número de facectomias realizadas atualmente. Em nossa casuística, cirurgia ocular, trauma penetrante e infecção sistêmica apareceram como fatores predisponentes para endoftalmite, concordante com a literatura ${ }^{(2)}$.

As endoftalmites pós-traumáticas, associadas à presença de corpos estranhos intra-oculares, partículas do solo ou vegetais, decorrem, geralmente, de infecções causadas por agentes anaeróbios, principalmente Clostridium perfrigens, $\mathrm{e}$ podem levar à perda do globo ocular em 24 horas $^{(5)}$. Dados do trabalho em questão mostram que 7 olhos (26\%) tinham ante- 


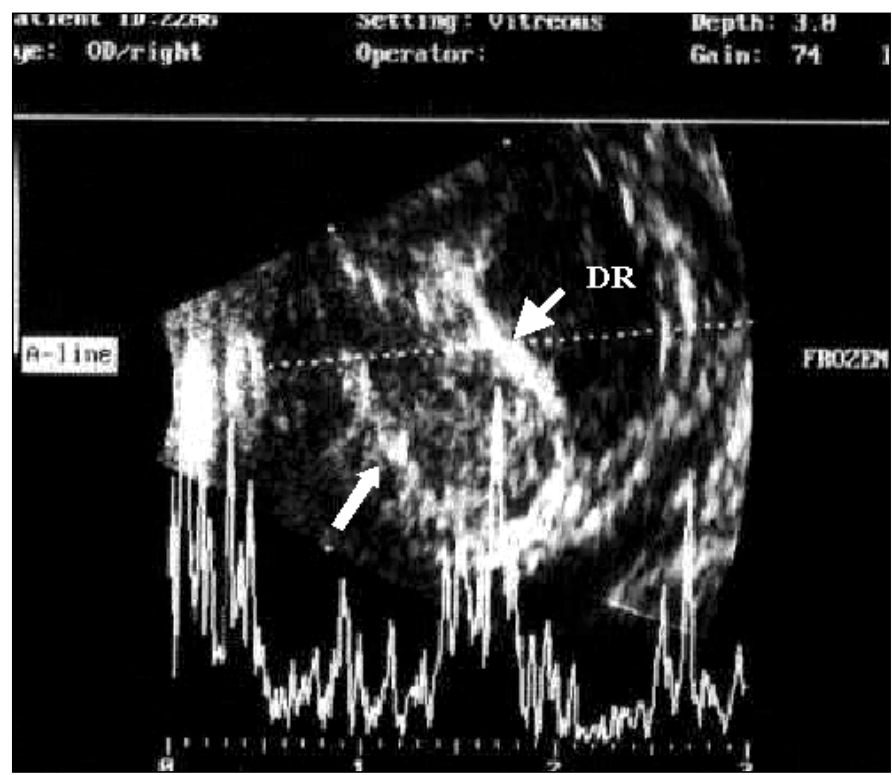

Figura 2 - Paciente com endoftalmite pós-úlcera de córnea apresenta múltiplas e densas membranas vítreas (seta larga) associadas a DR total (caso 10)

cedente de trauma ocular penetrante, sendo que em 3 casos que se seguiram a ferimentos com vegetal ou vidro, verificouse a presença de filamentos fúngicos leveduriformes no exame bacterioscópico da córnea.

As endoftalmites de causa endógena representam as formas menos comuns e ocorrem em indivíduos imunodeprimidos, diabéticos, usuários de drogas endovenosas, ou após infecções urinárias ou cardíacas e resultam de embolização séptica maciça ${ }^{(6)}$. Nos dois casos aqui relatados (8\%), a imunossupressão (diabetes e linfoma leucemizado) esteve presente.

Um grande número de condições com etiologias distintas como infecções virais (herpes simples, citomegalovírus), toxoplasmose, toxocaríase, neoplasias e outras podem produzir quadro semelhante a endoftalmite, com celularidade no vítreo e câmara anterior. Por vezes, não se consegue diferenciar pelo aspecto fundoscópico da lesão, se as apresentações não forem típicas.

A ultra-sonografia é um método útil na determinação do diagnóstico, tratamento e evolução da endoftalmite, principalmente quando não se pode avaliar o segmento posterior devido à opacidade de meios. Apesar do seu valor, há poucos relatos, principalmente na literatura nacional, quanto aos padrões ultrasonográficos observados nos casos de endoftalmite.

$\mathrm{Na}$ literatura mundial os relatos existem, embora as séries de casos não sejam grandes. Os achados citados na literatura incluem: ecos móveis de baixa refletividade (10-60\% do pico máximo), membranas vítreas, membranas ciclíticas, vítreo com padrão em forma de $\mathrm{H}$, imagens endovítreas de baixa refletividade, espessamento coroidal difuso ou nodular ${ }^{(1,7-8)}$.

Foram achados comuns a todos os casos da série em questão, a presença de ecos puntiformes ou membranáceos, múltiplos, de refletividade variável, mas predominantemente média, ocupando a cavidade vítrea na sua porção anterior,

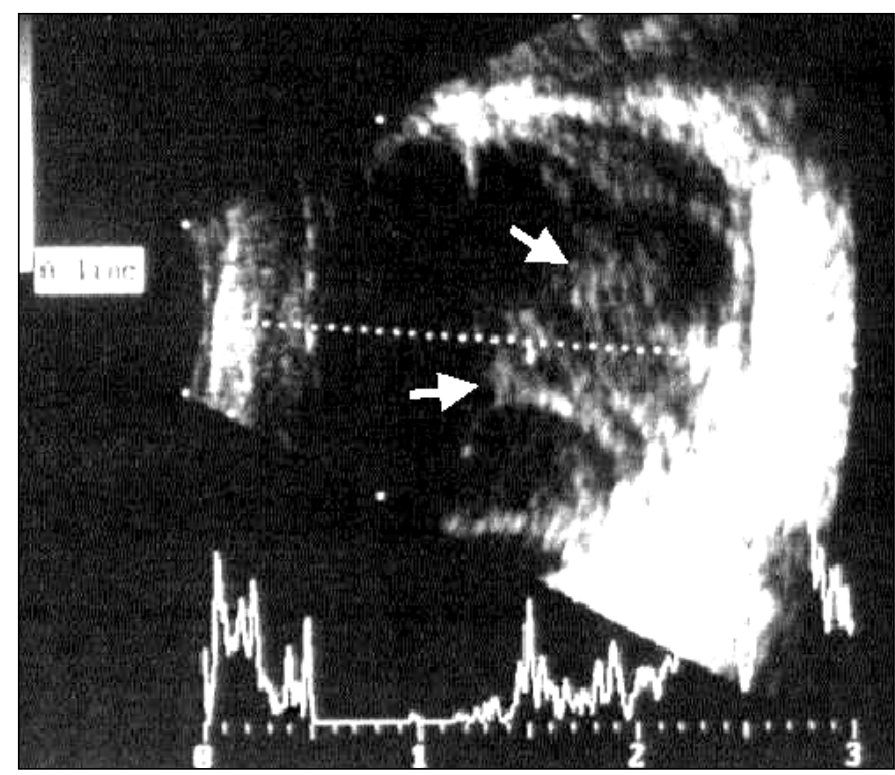

Figura 3 - Paciente com endoftalmite endógena apresenta ecos puntiformes e membranáceos organizados (setas), aderidos ao pólo posterior, associados a espessamento da coróide (caso 22)

média ou total. O grau de acometimento do vítreo pareceu ser proporcional à densidade destes ecos, ou seja, nos casos com acometimento exclusivo do segmento anterior, estes ecos eram tênues e esparsos, necessitando utilizar ganho mais alto ( $75 \mathrm{~dB}$ ao invés de $70 \mathrm{~dB}$ ) para torná-los mais visíveis (Casos 6 e 21). Nestes dois casos, em sendo os ecos de formas e amplitudes muito semelhantes aos do olho contra-lateral normal, afastou-se a hipótese de comprometimento infeccioso agudo do vítreo no exame ultra-sonográfico inicial. No caso 25 não houve progressão do processo, apesar do comprometimento puntiforme do vítreo e da presença de impregnação da hialóide ao ultra-som. O caso evoluiu com melhora clínica com o tratamento tópico. Poder-se-ia tratar de uma reação inflamatória entre o material visco-elástico residual e o vítreo (informação obtida do cirurgião) e não de caso infeccioso.

Num estudo de 11 casos de endoftalmite, os autores relataram a presença de debris e membranas no vítreo, e de descolamento da membrana hialóide posterior. Os debris eram mostrados como ecos múltiplos, esparsos ou puntiformes, dispostos por toda a cavidade vítrea ${ }^{(1)}$.

Numa análise de muitas variáveis, em 137 olhos com endoftalmite, os autores relataram 4 achados (opacidades vítreas densas, descolamento da retina, descolamento macular e descolamento da coróide) que, se presentes no exame ecográfico inicial, se correlacionariam às piores acuidades visuais. Já a visão final parecia estar relacionada, segundo os mesmos autores, à densidade das membranas vítreas, à presença de descolamento de retina, e à extensão do descolamento de retina e/ou da coróide ${ }^{(7)}$. A associação poderia ser explicada pela maior agressividade do agente etiológico, principalmente quando se tratava de bactérias Gram-negativas, que segundo estes autores, liberariam endotoxinas, causando o descola- 
mento precoce da coróide ${ }^{(7)}$. Apesar de não compararmos as acuidades visuais na nossa série, parece-nos que a densidade das membranas vítreas denotaria maior infiltração celular inflamatória com organização, e, concordando com os autores acima, dificultando a resolução para um bom prognóstico visual.

Nos estágios mais precoces pode haver dificuldade em se detectar alterações significativas ao ultra-som, daí a importância dos exames seriados. Há estudos que mostram mudanças evolutivas significativas à ultra-sonografia decorrentes da virulência do agente etiológico ${ }^{(8)}$. Nosso estudo não permitiu correlacionar os achados ultra-sonográficos à provável etiologia. Outros autores observaram que todos os olhos com vítreo claro ao ultra-som na fase inicial da endoftalmite, tinham cultura positiva para estreptococos ou cultura negativa. Observaram, ainda, que em 3 dias os exames sofriam grandes mudanças, daí, mais uma vez, a importância em se examinar precocemente e de se repetir seriadamente o exame de ultrasonografia nos casos de endoftalmite ${ }^{(7)}$.

Em nosso estudo, a reação vítrea condensada com mobilidade em bloco associada à presença de vacúolos intra-vítreos, esteve presente nos casos mais graves, alguns evoluindo com evisceração cirúrgica programada ou até espontânea.

Nos pacientes com endoftalmites fúngicas, a presença de vacúolos endovítreos de baixa refletividade corresponderiam a colônias fúngicas ${ }^{(8)}$.

Alterações na coróide estiveram presentes primária ou secundariamente (após punção, injeção intra-vítrea ou após cirurgia). Em sendo a coróide uma túnica vascular, o edema inflamatório, com coleção para o espaço supra-coroidal, dá um aspecto de espessamento difuso da mesma, facilmente identificável à ultra-sonografia. Este espessamento retinocoroidal visto nos casos de endoftalmite, é difícil de ser diferenciado do espessamento coroidal descrito nos casos de descolamento seroso da coróide ${ }^{(1)}$. Já o espessamento nodular localizado, que corresponderia a exsudação, formação de pequenos microabscessos e infiltração, típico da endoftalmite, não foi observado no estudo em questão, como referido por alguns autores ${ }^{(8)}$.

Os debris do vítreo nas suspeitas de endoftalmite, são difíceis de distinguir dos debris na hemorragia vítrea, exemplo disto foi o caso 20. Há um estudo que compartilha a mesma opinião $^{(1)}$. A evolução dos casos de hemorragia vítrea e dos casos de endoftalmite é diferente. Além de hemorragia vítrea, outras condições (vitreítes de diferentes etiologias) podem apresentar o mesmo padrão ultra-sonográfico, entretanto, quando estes achados estão presentes em paciente com história sugestiva de infecção, o diagnóstico de endoftalmite deve ser considerado.

Não foi possível correlacionar os achados ultra-sonográficos aos agentes etiológicos. Alguns casos tiveram o diagnóstico presumido. Nos casos de endoftalmite, a utilização de antibioticoterapia prévia à época do exame ultra-sonográfico, eventuais problemas relacionados a técnicas de colheita $\mathrm{e}$ cultura, a descontinuidade de seguimento, e a falta de descri- ção evolutiva (pacientes, em sua maioria, do pronto-socorro) contribuíram para limitar a identificação etiológica e a documentação da evolução final do caso.

Apesar das limitações do estudo, acreditamos que a ultrasonografia ocular é um método útil no diagnóstico do comprometimento do segmento posterior por processo infeccioso, devendo ser realizada nos casos suspeitos de endoftalmite para determinar o grau de envolvimento das estruturas do globo ocular e, desta maneira, auxiliando no tratamento e no acompanhamento do paciente.

\section{ABSTRACT}

Purpose: To determine ultrasonographic findings in patients with clinical diagnosis of endophthalmitis, a severe purulent inflammatory reaction confined to the interior of the eye. Methods: Ultrasound examination was performed $(10 \mathrm{MHz}$ transducer, UltraScan ${ }^{\circledR}$ ALCON), during the period of 1997 to 1999. Results: We analyzed 25 eyes with a clinical diagnosis of endophthalmitis ( 23 exogenous, 2 endogenous). Twelve (12/ 23 ) were post-surgery ( 7 post-cataract surgery, 4 post-glaucoma surgery and 1 post-keratoplasty). Six followed penetrating trauma and 4 were after corneal ulcer. One patient had corneal suture and cataract surgery after penetrating trauma. Two of them presented low-reflectivity echoes, similar to the normal vitreous, and endophthalmitis was ruled out at that time. Twenty-three cases presented (at different degrees) vitreous involvement with low-mobility dense membranes, vitreous organization and vitreous cavitation. Diffuse choroidal thickening ( 12 cases), choroidal and/or retinal detachment ( 8 and 5 cases) and orbital abscess (1 case) were found. Conclusions: Ultrasound examination is important to help in clinical suspected endophthalmitis in order to determine the involvement of the posterior segment.

Keywords: Endophthalmitis/ultrasonography; Eye infections; Ultrasonics

\section{REFERÊNCIAS}

1. Chan IM, Jalkh AE, Trempe CL, Tolentino FI. Ultrasonographic findings in endophthalmitis. Ann Ophthalmol 1984;16:778-84.

2. Shrader SK, Band JD, Lauter CB, Murphy P. The clinical spectrum endophthalmitis incidence, predisposing factors and features influencing outcome. $\mathrm{J}$ Infect Dis 1990;162:115-20.

3. Freda R, Gama JDC. Endoftalmite - revisão. Rev Bras Oftalmol 1995;54:35-40.

4. Molinari LC. Trauma ocular e endoftalmite. Rev Bras Oftalmol 1995;54:57-63.

5. Rehany U, Dorenboim Y, Lefler E, Schirer E. Clostridium bifermentans panophthalmitis after penetrating eye injury. Ophthalmology 1994;101:839-42.

6. Okada AA, Jonhson RP, Liles VC, D'Amico DJ, Baker AS. Endogenous bacterial endophthalmitis. Report of a ten-year retrospective study. Ophthalmology 1994;101:832-8.

7. Dacey MP, Valencia M, Lee MB, Dugel PU, Ober RR, Green RL, Lopez PF. Echographic findings in infectious endophthalmitis.[commented on Arch Opthalmol 1195;113:851-2]. Arch Ophthalmol 1994;112:1325-33.

8. Marchini G, Pagliarusco A, Tosi R, Castagna G. Ultrasonographic findings in endophthalmitis. Acta Ophthalmol Scand 1995;73:446-9. 